\title{
CORRELATION BETWEEN THE CHANGE IN ORBITAL VOLUME AND CORRECTION OF ENOPHTLAMOUS IN DELAYED POST-TRAUMATIC CASES
}

\author{
Yasmine Ahmed Nassar* and Adel Hamdy Abou-ElFetouh*
}

\begin{abstract}
Background: Post-traumatic enophthalmos is a multifactorial phenomenon that can be attributed to the increased orbital volume, loss of ligamental support of the globe or atrophy of orbital fat. Early restoration of orbital volume has been associated with an improvement in the maximal corneal projection and reduced enophthalmos. However, delayed repair of orbital fractures is more complicated due to the evident scarring of periorbital tissues.
\end{abstract}

Aim of the study: The aim of this study was to correlate post-operative correction of the corneal projection to the degree of correction (decrease) of the orbital volume after delayed repair of orbital fractures.

Patients and Methods: Ten patients suffering from unilateral orbital fracture who were treated one month or more from the date of trauma were included in this study. All patients received a preoperative $\mathrm{CT}$ that was imported into a surgical planning software to quantify the preoperative orbital volume as well as the maximal corneal projection of the traumatized orbit. One-month postoperatively, the patients received another CT scan to once again quantify the reconstructed orbital volume and to record any improvement in the maximal corneal projection. Results were recorded in the form of means \pm standard deviation and Pearson's correlation coefficient was implemented to analyze the correlation between the change in the orbital volume and the change in the degree of enophthalmos.

Results: The mean decrease in the orbital volume was $4.27 \mathrm{~cm}^{3} \pm 3.60$ while the mean increase in corneal projection was $2.24 \mathrm{~mm} \pm 1.16$. Statistical analysis revealed a strong positive correlation between the forward translation of the maximal corneal projection and the change (decrease) in the orbital volume following reconstruction with a correlation coefficient $(R)$ value of 0.82 which indicated strong correlation. The value of $R^{2}$, the coefficient of determination is 0.67 . The $P$ value was 0.0125 which was significant at levels $<0.05$.

Conclusions: From the current study, it can be concluded that even in delayed cases the accurate reconstruction of the bony walls resulting in a decrease in the orbital volume is an important factor in correcting post-traumatic enophthlamos, as both variables showed a strong correlation to each other.

* Lecturer of Oral and Maxillofacial Surgery, Faculty of Dentistry, Cairo University. 


\section{INTRODUCTION}

So many factors have been accused of being the reason for post-traumatic enophthalmos. Studies have tried to figure out the main reason for such an esthetically unacceptable sequel. Among these explanations, was the amount of the herniated fat ${ }^{1}$, the orbital tissue atrophy ${ }^{2}$, the loss of the ligamental support of the globe $^{3}$ and the increase in orbital volume ${ }^{4}$.

So much attention has been given to the bony reconstruction of the orbital walls. Calvarial bone grafts $^{5}$, high density porous polyethylene alone ${ }^{6}$ or with embedded titanium meshes ${ }^{7}$, polydioxanone ${ }^{8}$ and titanium meshes ${ }^{9}$ are among the most popular grafts and implants used for reconstruction. Optimizing the bony reconstruction using advanced techniques such as intraoperative imaging, navigation and computer-assisted planning have been reported over the past years ${ }^{10,11}$.

But the question is; does restoration of the orbital volume positively correlate to the correction of enophthalmos in delayed post-traumatic cases where scarring of tissues has occurred?

Therefore, the aim of this study was to correlate the post-operative correction of the corneal projection to the degree of correction (decrease) of the orbital volume.

\section{PATIENTS AND METHODS}

Ten patients presenting with delayed (more than one month after trauma) unilateral orbital fractures were selected from the outpatient clinic of the Oral and Maxillofacial department, Cairo University. Clinical examination was performed to detect different pupillary levels (hypophthalmos) and the presence of enophthalmos. All patients were instructed for a preoperative CT scan of a minimal slice thickness/ spacing, to evaluate the orbital walls and their need for reconstruction and to calculate the preoperative orbital volumes and measure the maximal corneal projection.
Prior to their admission to the operating room (OR) the patients underwent routine laboratory investigations.

All surgeries were done under general anesthesia. Patients were scrubbed and draped according to the standard technique. The orbital floor was approached using a transconjunctival (post-septal) approach or a subciliary approach. Dissection was performed till an intact shelf of bone was revealed. A titanium mesh (Synthes, $0.4 \mathrm{~mm}$ rigid) was then introduced to reconstruct the orbital wall(s) and fixed in place using micro screws. Transconjunctival incisions were sutured using 6-0 vicryl sutures, while subciliary incisions was closed in layers; deep layers were closed using 4-0 Vicryl sutures and the skin using 6-0 polypropylene sutures

A suspension suture to hold the lower eyelid was performed whenever a transconjunctival approach was used. The patient was prescribed Ampicillin/ Sulbactam $1500 \mathrm{mg}$ IM q12h for 2 days followed by Amoxicillin/Clavulanic acid $1000 \mathrm{mg}$ q12h for 7 days, Diclofenac Sodium 75mg IM for 2 days followed by Diclofenac Sodium $50 \mathrm{mg}$ tablets $\mathrm{q} 8 \mathrm{~h}$, and $80 \mathrm{mg}$ of Methylprednisolone acetate before discharge on the day of surgery were prescribed.

Follow up of the patients was performed for removal of the suspension suture 3 days postoperatively, and for the skin staples at 10 days postoperatively.

A postoperative $\mathrm{CT}$ was performed one month postoperatively with the same parameters as the preoperative one, upon which segmentation of the intraorbital contents, calculation of the orbital volume (figures 1-3) and measurement of the maximal corneal projection (figure 4) were executed using Mimics software (Matreialise inc., Leuven, Belgium).

The decrease in the orbital volume was then calculated by subtraction the post-operative volume from the preoperative one. In addition, the forward movement of the maximal corneal projection was calculated by subtracting the preoperative value 


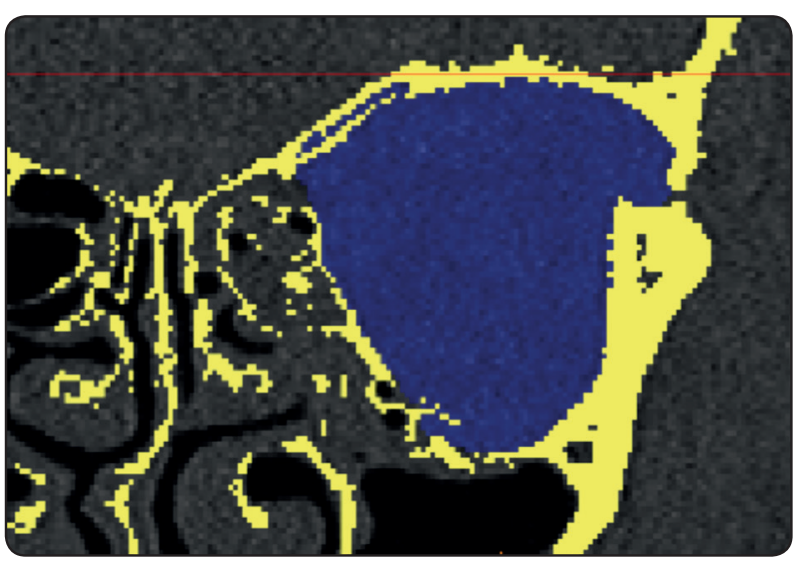

Fig. (1) A coronal CT cut showing segmentation of the intraorbital content (blue) from the surrounding bony orbit (yellow).

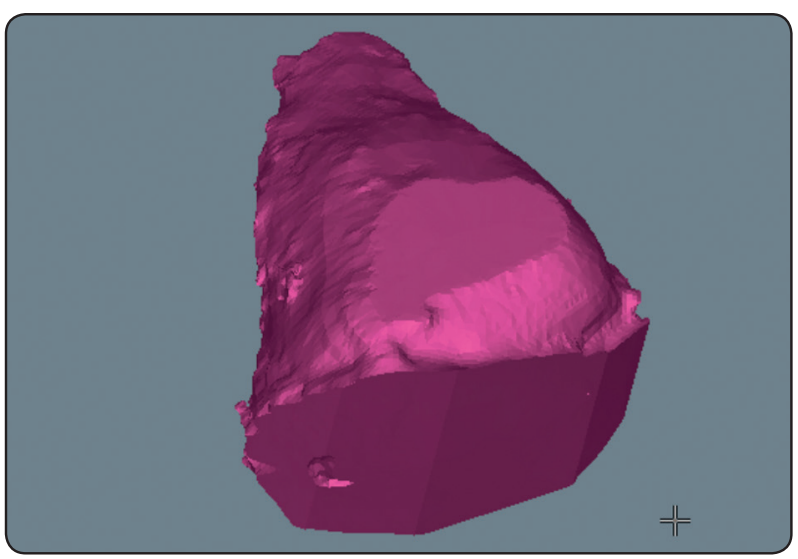

Fig. (3) A 3D image of segmented orbital contents.

from the post-operative value, which revealed the correction of enophthalmos.

Statistical analysis was performed using SPSS (Statistical Package for the Social Sciences) version 20, IBM corp., U.S.A. Data were expressed in term of means \pm standard deviation. The correlation between forward translation of the corneal projection (correction of enophthalmos) and change (decrease) in orbital volume was done using Pearson's correlation factor. The significance level $(P$ value $)$ is 0.05 .

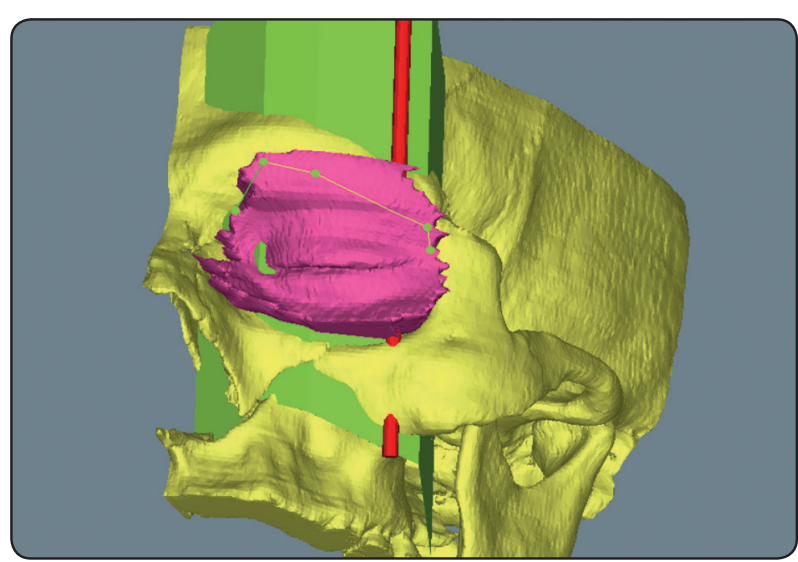

Fig. (2) A cutting plane passing within the orbital rim and separating the orbital contents from the soft-tissue situated outside the boundaries of the bony orbit.

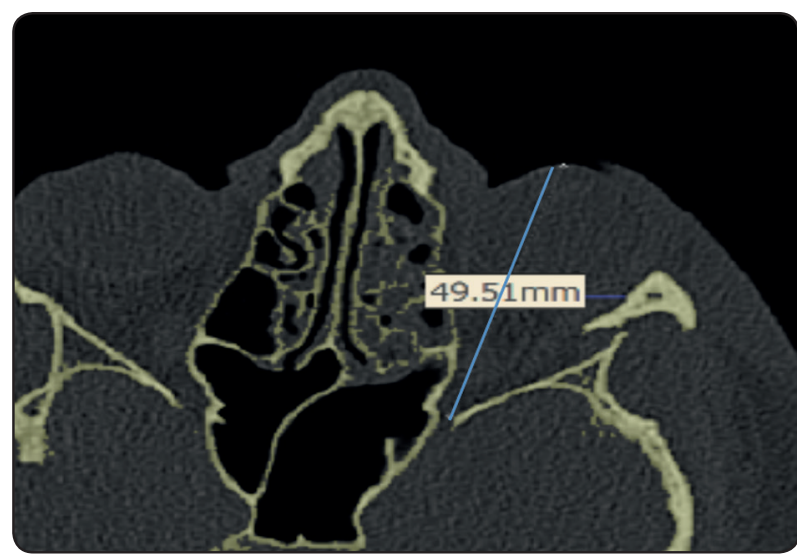

Fig. (4) An axial CT scan cut showing the linear measurement of the maximal corneal projection, by extending a line between the corneal surface and the superior orbital fissure.

\section{RESULTS}

The healing period went uneventful for all cases, apart from two cases. One showed a hypertrophic scar following the subciliary approach and the other an increased scleral show following the transconjunctival approach.

The mean decrease in the orbital volume was $4.27 \mathrm{~cm}^{3} \pm 3.60$ while the mean increase in corneal projection was $2.24 \mathrm{~mm} \pm 1.16$. Statistical analysis revealed a strong positive correlation between the forward translation of the maximal corneal 
projection ( $Y$ value) and the change (decrease) in the orbital volume following reconstruction ( $X$ value) (Figure 5) with a correlation coefficient; $R$ value of 0.82 which indicates this strong correlation as illustrated in figure 6 . The value of $R^{2}$, the coefficient of determination is 0.67 . The $P$ value was 0.0125 which was significant at levels $<0.05$. Regression Analysis showed that the relation between the changes in orbital volume $(X)$ and orbital projection $(Y)$ could be represented by the following equation:

$$
Y=0.2649 X+1.105
$$

TABLE (1) A table explaining the significance of $R$ values in Pearson's correlation coefficient, where values above zero indicate a positive correlation between the variables. An $\mathrm{R}$ value rangeing from 0.8 -1 suggests a strong correlation between variable. ${ }^{12}$

\begin{tabular}{|c|c|c|}
\hline & \multicolumn{2}{|c|}{ Coefficient $\mathbf{r}$} \\
\hline Strong & 1 to 0.8 & -0.8 to -1 \\
\hline Moderate & 0.8 to 0.5 & -0.5 to -0.8 \\
\hline Weak & 0.5 to 0.3 & -0.3 to 0.5 \\
\hline No Correlation & 0.3 to 0 & 0 to -0.3 \\
\hline
\end{tabular}

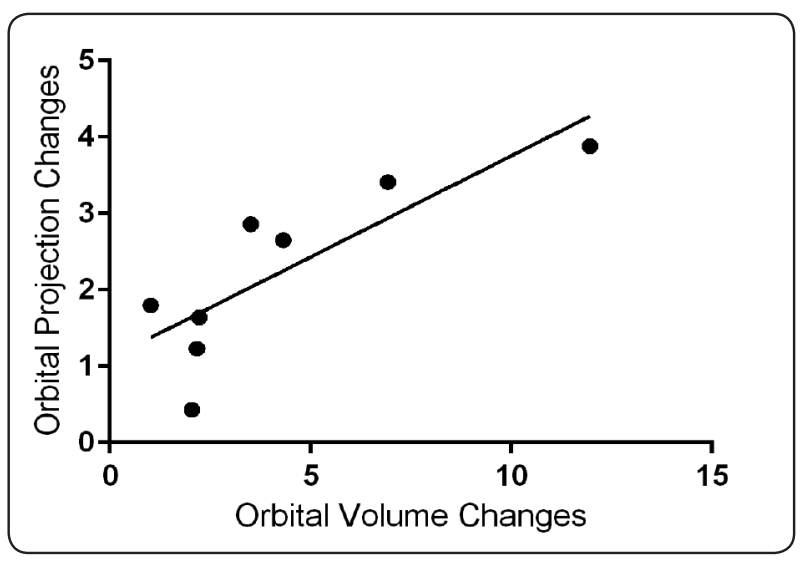

Fig. (5) Scatterplot and line of best fit for orbital volume vs orbital projection changes.

\section{DISCUSSION}

Cases of orbital fractures presenting late for treatment are more complicated than those presenting early since there is an added factor which is the increased adhesion and scarring of the periorbital soft tissues. Therefore, it was important to investigate whether reconstruction of the orbital volume in delayed cases would still positively affect the globe position or not.

The use of CT scans has proven to be useful in careful examination and accurate measurements involving the orbital walls ${ }^{13}$. It's can protect the patient from an undue surgical exploration, as the CT scan reveals accurately even the fractures of the thinnest of all which is the medial wall of the orbit ${ }^{14}$.

In this study standardization of the calculated orbital volume was ensured by segmenting the area contained within the bony orbital cavity and using a poly-planar cutting plane, which followed the superior and inferior orbital margins, all tissues beyond the bony margins were separated, thereby making sure that only the orbital bony volume had been calculated. This is a novel technique not mentioned in previous reports.

The corneal projection measurements depended on two points that are guaranteed intact in all included cases. Measurements of the corneal projection using Hertel exophthalmometers as reported before might not be optional in cases where the lateral orbital margin is severely displaced.

The present study has shown that the decrease in orbital volume correlates to the increase in the corneal projection and correction of enopthalmos as observed in the scatterplot and that this correlation is strong as denoted by the $R$ value; 0.82 . The results showed a statistically significant correlation with $P$ value $<0.05$ i.e the relationship between the two variables (volume and projection) is significant. 
In the current study the correlation was performed between the surgically reconstructed orbital volume and the post-operative correction of enophthalmous, Ye et $\mathrm{al}^{15}$ and Kolk et $\mathrm{al}^{16}$ too, correlated the post-operative values. Whitehouse et $\mathrm{al}^{17}$, Raskin et $\mathrm{al}^{18}$ and Fan et $\mathrm{al}^{19}$ on the other hand correlated the clinically presenting pre-operative enophthalmous to the increase in the orbital volume due to trauma preoperatively.

The mean orbital volume decrease in the present study was $4.27 \mathrm{~cm}^{3} \pm 3.60$ while the mean increase in corneal projection was $2.24 \mathrm{~mm} \pm 1.16$. Ye et a ${ }^{15}$ had comparable means, with a mean decrease in volume of $4.08 \pm 2.45 \mathrm{~cm}^{3}$ and the decrease in enophthalmous was $1.19 \pm 1.05 \mathrm{~mm}$. Using the mean decrease in volume in the regression equation can be explained as follows, a $4.27 \mathrm{~cm}^{3}$ decrease in volume would result in a $2.21 \mathrm{~mm}$ improvement in the corneal projection. Ye et $\mathrm{al}^{15}$ on the other hand reported that for a $2 \mathrm{~mm}$ of correction of enophthalmous the orbital volume need a $2.86 \mathrm{~cm}^{3}$ of volumetric correction.

Whitehouse et $\mathrm{al}^{17}$ presented their regression analysis of a sample of their cases as follows; $\mathrm{E}=0.77 \mathrm{~V}-0.68$, while Fan et $\mathrm{al}^{19}$ as follows; $\mathrm{E}=0.89 \mathrm{~V} \pm 0.08$ (where $\mathrm{E}=$ Enophthalmous in $\mathrm{mm}$ and $\mathrm{V}=$ Orbital volume in $\left.\mathrm{cm}^{3}\right)$. In the interpretation of their results Whitehouse et $\mathrm{al}{ }^{17}$ reported that every $1 \mathrm{~cm}^{3}$ increase in volume corresponded to $0.8 \mathrm{~mm}$ of enophthalmous, while Fan et $\mathrm{al}^{19}$ mentioned that every $1 \mathrm{~cm}^{3}$ increase due to trauma led to an 0.89 mm enophthalmous.

Similarly, Jin et $\mathrm{al}^{14}$ reported an $0.85 \mathrm{~mm}$ correction of enophthalmos and Kolk et al ${ }^{16}$ reported an $0.93 \mathrm{~mm}$ enophthalmous for every $1 \mathrm{~cm}^{3}$, while Raskin et $\mathrm{al}^{18}$ reported an $0.47 \mathrm{~mm}$ enophthalmos corresponding to each $1 \mathrm{~cm}^{3}$ change in volume.

All the aforementioned studies agreed upon the strong correlation between enophthalmous and the changes that occur in the orbital volume, with $R$ values ranging from 0.8 to 0.95 .

\section{CONCLUSIONS}

From the current study we can conclude that even in delayed cases the accurate reconstruction of the bony walls resulting in a decrease in the orbital volume is an important factor in correcting posttraumatic enophthlamos, as both variables show a strong correlation to each other.

\section{REFERENCES}

1. Zhang Z, Zhang Y, He Y, An J, Zwahlen RA. Correlation between volume of herniated orbital contents and the amount of enophthalmos in orbital floor and wall fractures. J Oral Maxillofac Surg. 2012 Jan;70(1):68-73.

2. Kim SM, Jeong YS, Lee IJ, Park MC, Park DH. Prediction of the development of late enophthalmos in pure blowout fractures: delayed orbital tissue atrophy plays a major role. Eur J Ophthalmol. 2017 Jan 19;27(1):104-108.

3. Manson PN, Clifford CM, Su CT, Iliff NT, Morgan R. Mechanisms of global support and posttraumatic enophthalmos: I. The anatomy of the ligament sling and its relation to intramuscular cone orbital fat. Plast Reconstr Surg. 1986 Feb;77(2):193-202.

4. Choi SH, Kang DH, Gu JH. The Correlation between the Orbital Volume Ratio and Enophthalmos in Unoperated Blowout Fractures. Arch Plast Surg. 2016Nov; 43(6):518522 .

5. Pereira Rdos S, Jorge-Boos FB, Hochuli-Vieira E, da Rocha HV Jr, Homsi N, deMelo WM. Management of pure medial orbital wall fracture with autogenous bone graft. J Craniofac Surg. 2013;24(5):e475-7

6. Kang SJ, Kim JW. Surgical treatment of enophthalmos using an endoscope and T-shaped porous polyethylene fabricated with a mirror image. Int J Oral Maxillofac Surg. 2012 Oct;41(10):1186-91

7. Kim CY, Jeong BJ, Lee SY, Yoon JS. Comparison of surgical outcomes of large orbital fractures reconstructed with porous polyethylene channel and porous polyethylene titan barrier implants. Ophthal Plast Reconstr Surg. 2012 May-Jun;28(3):176-80.

8. Beck-Broichsitter BE, Acar C, Kandzia C, Jochens A, Wiltfang J, Becker ST. Reconstruction of the orbital floor with polydioxanone: a long-term clinical survey of up to 12 years. Br J Oral Maxillofac Surg. 2015 Oct;53(8): 736-40. 
9. Raisian S, Fallahi HR, Khiabani KS, Heidarizadeh M, Azdoo S. Customized titanium mesh based on the 3D printed model vs. manual intraoperative bending of titanium mesh for reconstructing of orbital bone fracture: a randomized clinicaltrial. Rev Recent Clin trials. 2017 Aug 21.

10. Azarmehr I, Stokbro K, Bell RB, Thygesen T. Surgical Navigation: A Systematic Review of Indications, Treatments, and Outcomes in Oral and MaxillofacialSurgery. J Oral Maxillofac Surg. 2017 Sep; 75(9):1987-2005

11. Susarla SM, Duncan K, Mahoney NR, Merbs SL, Grant MP. Virtual Surgical Planning for Orbital Reconstruction. Middle East Afr J Ophthalmol. 2015 Oct-Dec;22(4):442-6.

12. https://www.google.com.eg/search?tbm=isch\&sa=1\&ei=T ZYnWoqeCsutazToKAJ\&q=strength+of+correlation\&oq =strength+\&gs_l=psyab.1.0.0i67k1j012j0i67k1j012j0i67k $112 \mathrm{j} 012.26545 .31305 .0 .33160 .58 .14 .0 .3 .3 .0 .437 .1634 .0 \mathrm{j} 3$ j0j1j2.7.0...0...1c.1.64.psyab..49.7.1299.0..488.ZOeFW fBMm9g\#imgdii=jcwPsaGhByMl_M:\&imgrc=OZt1SZ RV_dokXM:

13. Betts AM, O’Brien WT, Davies BW, Youssef OH. A systematic approach to CT evaluation of orbital trauma. Emerg Radiol. 2014 Oct;21(5):511-31.

14. Jin HR, Shin SO, Choo MJ, Choi YS. Relationship between the extent of fracture and the degree of enophthalmos in isolated blowout fractures of the medial orbital wall. J Oral Maxillofac Surg. 2000 Jun;58(6):617-20; discussion $620-1$.

15. Ye J, Kook KH, Lee SY. Evaluation of computer-based volume measurement and porous polyethylene channel implants in reconstruction of large orbital wall fractures. Invest Ophthalmol Vis Sci. 2006 Feb;47(2):509-13

16. Kolk A, Pautke C, Schott V, Ventrella E, Wiener E, Ploder O, Horch HH, Neff A.Secondary post-traumatic enophthalmos: high-resolution magnetic resonance imaging compared with multislice computed tomography in postoperative orbital volume measurement. J Oral Maxillofac Surg. 2007 Oct;65(10):1926-34.

17. Whitehouse RW, Batterbury M, Jackson A, Noble JL. Prediction of enophthalmos by computed tomography after 'blow out' orbital fracture. Br J Ophthalmol. 1994 Aug;78(8):618-20.

18. Raskin EM, Millman AL, Lubkin V, della Rocca RC, Lisman RD, Maher EA. Prediction of late enophthalmos by volumetric analysis of orbital fractures. Ophthal Plast Reconstr Surg. 1998 Jan;14(1):19-26

19. Fan X, Li J, Zhu J, Li H, Zhang D. Computer-assisted orbital volume measurement in the surgical correction of late enophthalmos caused by blowout fractures. Ophthal Plast Reconstr Surg. 2003 May;19(3):207-11. 